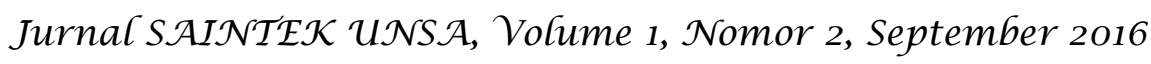

\title{
STUDI PERENCANAAN TEKNIS BANGUNAN PENGENDALI SEDIMEN PADA SUNGAI MOYO KABUPATEN SUMBAWA
}

\author{
DIDIN NAJIMUDDIN ${ }^{1}$, ADY PURNAMA ${ }^{2}$, ARI WIJAYA ${ }^{3}$ \\ Dosen Program Studi Teknik Sipil Fakultas Teknik Universitas Samawa Sumbawa Besar ${ }^{1,2}$ \\ Mahasiswa Program Studi Teknik Sipil Fakultas Teknik Universitas Samawa Sumbawa Besar ${ }^{3}$
}

\section{ABSTRAK}

Penelitian ini dilakukan di sungai moyo,yang terletak di kecamatan Moyo, Sungai ini memiliki luas Daerah Pengaliran Sungai (DPS) 117.090 km2 dengan panjang 27.530 km2 sungai ini memliki sedimen yang cukup besar,sehingga berpotensi pendangkalan di daerah genagan bendung dan akan mengancam kelangsungan fungsi bendung itu sediri. Hal inilah yang kemudian mendasari perlu di lakukan perencanaan bangunan Pengendali sedimen di sungai ini. Adapun pemilihan bangunan Berupa Cek dam yang terletak dibagian hulu sungai itu sendiri.

Adapun metode yang digunakan pada penelitian ini adalah dengan melakukan survey langsung ke lokasi serta pengumpulan data-data sekunder dari intansi terkait. Adapun data yang di butuhkan dalam perhitungan berupa data curah hujan, data topograpi,serta data lain berkaitan dengan morpologi sungai. Dari data tersebut kemudian di peroleh nilai hujan Rancangan, debit banjir rancangan, dimensi disain hidrolis bangunan.

Berdasarkan penelitian Penelitian studi perencanaan bangunan pengendali sedimen ini dimulai dari analisa hidrologi, hidraulika serta stabilitas konstruksinya. Berdasarkan perhitungan yang telah dilakukan bangunan pengendali sedimen. Direncanakan memiliki fisik seperti sebagai berikut elevasi puncak mercu pelimpah pada elevasi +28.300 m dengan ketingian efektif $3.5 \mathrm{~m}$ dengan kedalaman pondasi $2.25 \mathrm{~m}$ lebar mercu pelimpah di dapatkan 20 m,kontruksi berupa Pasangan Batu dengan di rencanakan priode ulang $Q 50$ tahun Sebesar $217.150 \mathrm{~m} 3 / \mathrm{dt}$.

Kata kunci : Sedimen, Bangunan Pengendali, Sungai Moyo.

\section{PENDAHULUAN}

Daerah Aliran Sungai (DAS) merupakan suatu area yang berfungsi sebagai daerah penampung air hujan, daerah resapan air, daerah penyimpanan air, penangkap air hujan dan pengaliran air yang kesemuanya itu membentuk sebuah sungai.

Sungai merupakan salah satu kekayaan alam yang sangat berperan dalam membentuk corak kehidupan suatu masyarakat. Ketersediaan air dan potensipotensi yang terkandung di dalamnya menarik manusia untuk memanfaatkannya. Hampir seluruh sungai yang ada di setiap wilayah dimanfaatkan untuk memenuhi kepentingan hajat hidup manusia. Antara lain untuk keperluan pengairan dan irigasi, untuk persediaan air bersih, pembangkit tenaga listrik dan transportasi, perikanan, atau bahkan hingga keperluan rekreasi.

Wilayahnya biasanya dibatasi oleh titiktitik tertinggi disekitarnya hingga kedaerah pesisir, yang meliputi hutan, pegunungan, ataupun pemukiman. Salah satu permasalahan yang lazim dialami DAS adalah semakin berkurangnya vegetasi penutup tanah yang menyebabkan terjadinya erosi hingga longsoran di sekitar aliran sungai.

Erosi dan longsoran inilah yang kemudian akan masuk kedalam sungai dan terbawa sebagai sedimen. Pendangkalan, perubahan morfologi sungai, hingga luapan air 
yang tak terkendali adalah contoh akibat yang dapat timbul jika terjadi penumpukan sedimen yang berlebih pada sungai tersebut. Untuk mengatasi masalah tersebut, biasanya dilakukan upaya normalisasi dengan pengerukan. Akan tetapi, upaya ini tentu saja membutuhkan biaya yang tidak sedikit sebab dilakukan berulang - ulang sehingga perlu di cari alternative penanganan lain yang lebih efektif dan efisien. Untuk menangani sedimen tersebut, biasa dilakukan dengan mengadakan penghijauan pada daerah aliran sungai agar erosi yang ada bisa berkurang. Akan tetapi, cara ini tentu saja membutuhkan waktu yang cukup lama sehingga perlu diambil tindakan penanganan sedimen dengan segera, yakni dengan membangun beberapa jenis bangunan pengendali sedimen agar masalah tersebut bias diatasi dengan segera. Salah satu jenis bangunan pengendali sedimen yang akan digunakan untuk menangani sedimen tersebut adalah bangunan pengendali sedimen dipilihnya bangunan ini di dasarkan pada kondisi yang telah diuraikan diatas, dimana akan diletakkan paling dekat dengan bagian hulu sungai dan sedimen yang akan ditanggulangi berupa sedimen yang berukuran besar.

berdasarkan dari uraian diatas, maka penulis kemudian tertarik untuk mengangkat tema tersebut kedalam tugas akhir yang kemudian diberi judul

\section{"Studi perencanaan teknis bangunan pengendali sedimen pada sungai Moyo"}

\section{METODE PENELITIAN}

Studi ini dilakukan pada daerah aliran sungai moyo yang berada di kecamatan moyo hilir, seperti yang tampak pada gambar 1 :

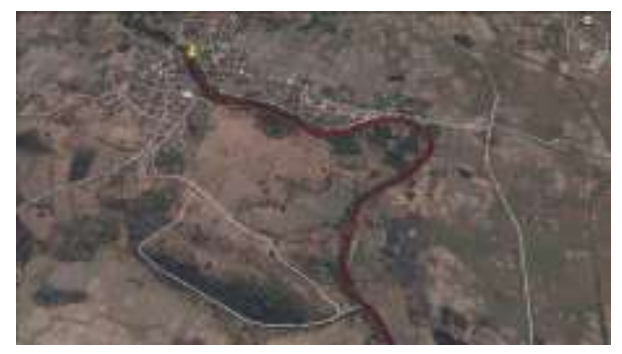

Gambar 1.Lokasi penelitian ( Google eart,2016)
Adapun metode yang digunakan dalam penelitian ini adalah metode deskriptif berupa studi kasus. Survey di lapangan dilakukan Antara bulan Maret-Agustus yang dilanjutkan dengan pengolahan data dan pembuatan desain hidrolis Bangunan Pengendali Sedimen. Pemilihan lokasi survei didasarkan pada kondisi sungai yang sesuai dengan studi yang dilakukan, yaitu untuk mengamati laju sedimen serta erosi yang terjadi di sekitar DAS Sungai Moyo.

\section{Jenis dan Sumber Data}

Jenis data yang digunakan dalam studi kasus ini berupa data kualitatif dan data kuantitatif. Contoh data kualitatif yang digunakan seperti kondisi DAS yang terkena erosi, serta laju sedimentasi yang terjadi pada sungai tersebut. Sedangkan data kuantitatif, digunakan data-data seperti data curah hujan, luasan DAS Moyo, data morfologi sungai.

Untuk sumber data, digunakan data berupa data primer dan sekunder. Data primer adalah data yang diperoleh dari survey langsung di lapangan. Sedangkan data sekunder berupa catatan yang sifatnya valid dan telah ada sebelumnya, yang didapatkan melalui instansi-instansi setempat yang terkait dengan studi ini.

\section{Teknik Pengumpulan Data}

Untuk mengumpulkan data primer, dilakukan survey dan pengukuran langsung di lapangan. Data yang dikumpulkan juga dilengkapi dengan hasil wawancara yang bersumber dari pihakpihak yang dirasa dapat membantu untuk memberikan informasi. Kegiatan survei dan pengukuran ini juga dilengkapi dengan dokumentasi. Adapun untuk data sekunder, dikumpulkan dari berbagai instansi-instansi terkait yang memiliki data yang diperlukan dalam studi ini.

\section{Analisa Data Hidrologi}

Data hidrologi yang diperoleh selanjutnya akan dianalisis untuk mencari debit banjir yang digunakan pada perencanaan bangunan pengendali 
sedimen Langkah - langkah dalam analisis hidrologi tersebut yaitu :

1. Perhitungan curah hujan wilayah.

2. Perhitungan curah hujan rancangan

3. Uji sebaran menggunakan Chi square test.

4. Perhitungan debit banjir rancangan, dengan metode Log Pearson Type III.

\section{Perencanaan Desain Bangunan Pengendali Sedimen}

Setelah melakukan analisis data hidrologi, selanjutnya dilakukan perencanaan desain hidrolis bangunan pengendali sedimen mengingat belum adanya standar perhitungan husus desain bangunan pengendali sedime yang telah dibukukan, maka untuk menentukan detail konstruksi, diambil referensi dari pedoman perencanaan yang dikeluarkan oleh kementrian pemukiman dan prasarana wilayah, serta dari berbagai referensi yang terkait dengan perancangan bangunan pengendali sedimen.

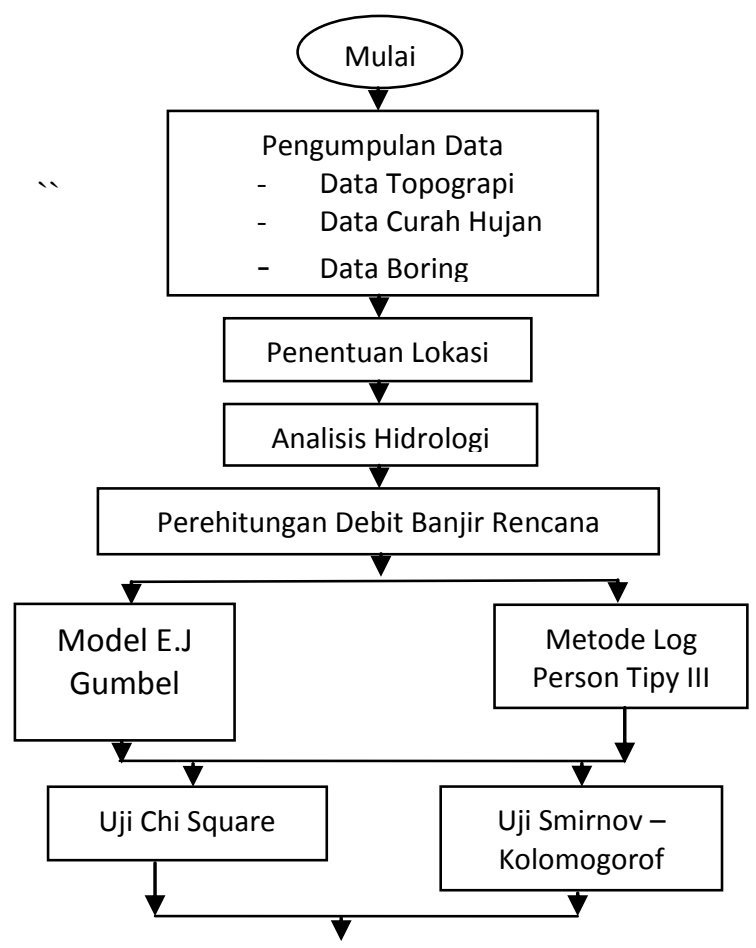

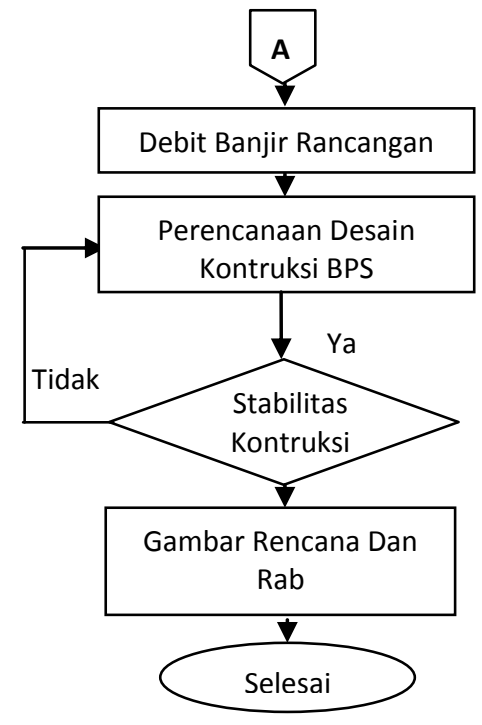

ANALISIS DAN PEMBAHASAN

Secara umum analisa hidrologi adalah melakukan analisa hidroklimatologi dengan teknik analisa secara kuantitatif yang mengacu pada berbagai metode yang relevan dengan Standar Nasional Indonesia yang berlaku. Dengan memperhatikan berbagai karakteristik geografis yang terkait,diharapkan dapat diperoleh informasi besaran hidrologi yang diperlukan untuk perencanaan Bangunan pengedali Sedimen.

Analisa data ini dimaksudkan untuk mendukung penentuan curah hujan rancangan, debit banjir rancangan serta karakteristik hidrologi lainnya. Adapun data curah hujan yang di perlukan adalah curah hujan harian. Lingkup pekerjaan analisa hidrologi meliputi analisa data, analisa hujan rancangan dan perhitungan transfer hujan ke debit banjir rancangan. Hasil dari analisa hidrologi ini adalah debit banjir rancangan dengan berbagai periode ulang.

Dalam perencanaan Bangunan pengedali Sedimen analisis hidrologi merupakan faktor penting untuk menentukan

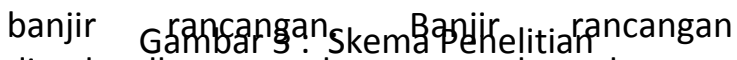
dimaksudkan untuk menentukan besaran erosi dan sedimentasi yang digunakan sebagai acuan dalam perencanaan bangunan Bangunan pengedali Sedimen. Tahapan dalam analisis hidrologi adalah analisis data curah hujan dan analisis debit banjir rancangan. 
Jurnal SAIJ $\mathcal{N}$ EK UNS A, Volume 1, $\mathcal{N}$ omor 2, September 2016

Banjir rancangan ditetapkan melalui analisis hidrologi dari sungai moyo dengan periode ulang tertentu sesuai dengan kriteria desain yang digunakan.

\section{Analisis Perhitungan Curah Hujan Rancangan}

Pada penelitian ini digunakan data curah hujan selama Dua Belas tahun yang tercatat mulai tahun 2004 sampai dengan 2015 pada stasiun Moyo Hilir. Data Curah Hujan secara lengkap ditunjukkan tabel 1 di bawah ini :

\section{Perhitungan Curah Hujan Rancangan Metode E.j Gumbel}

Tabel 1 : Perhitungan curah hujan rancangan metode E.j Gumbel

\begin{tabular}{|c|c|c|c|c|}
\hline No. & $\mathbf{X i}$ & $\begin{array}{c}\mathbf{X i} \\
\text { terurut }\end{array}$ & $\mathbf{P}(\boldsymbol{\%})$ & $\mathbf{X}_{\mathbf{i}}^{\mathbf{2}}$ \\
\hline 1 & 69 & 21 & 92.31 & 441.0 \\
2 & 79 & 30 & 84.62 & 900.0 \\
3 & 105 & 62 & 76.92 & 3844.0 \\
4 & 62 & 69 & 69.23 & 4761.0 \\
5 & 30 & 78 & 61.54 & 6084.0 \\
6 & 21 & 79 & 53.85 & 6241.0 \\
7 & 78 & 82 & 46.15 & 6724.0 \\
8 & 93 & 89 & 38.46 & 7921.0 \\
9 & 99 & 93 & 30.77 & 8649.0 \\
10 & 82 & 99 & 23.08 & 9801.0 \\
12 & 89 & 105 & 7.69 & 11025.0 \\
\hline Jumlah & & 910 & & 77000 \\
Rerata & & 75.83 & & 6417 \\
Std. Deviasi & 26.954 & & \\
\hline
\end{tabular}

Dari pengelolahan Data Curah hujan maka di dapatkan nilai Rata $75.83(\mathrm{~mm})$ dan Standar Deviasi 26.954 (mm) Perhitungan Secara lengkap dapat dilihat pada lampiran.

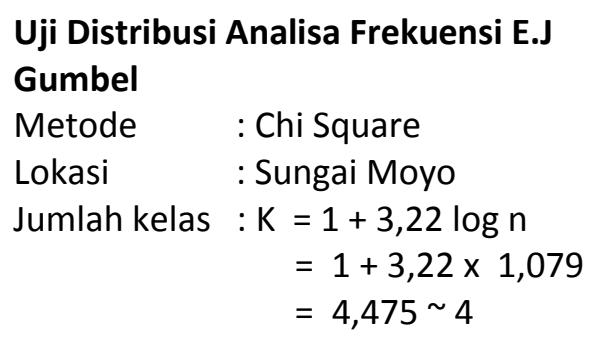

Distribusi Tiap kelas 100\% k $=100 \% / 4$

$$
=25 \%
$$

Tabel. 2 Uji Distribusi Analisa Frekuensi E.J Gumbel

\begin{tabular}{|c|c|c|c|c|c|c|c|c|c|}
\hline \multirow{2}{*}{$\mathrm{N}_{0}$} & \multicolumn{2}{|c|}{ Distribusil Prob. } & \multirow{2}{*}{ Yt } & \multirow{2}{*}{ K } & \multirow{2}{*}{\multicolumn{2}{|c|}{ Interval Kelas }} & \multirow[b]{2}{*}{ Ej } & \multirow[b]{2}{*}{$0 \mathrm{j}$} & \multirow{2}{*}{$\left(0 j \cdot E_{j}\right)^{2} \mathbb{E}$} \\
\hline & $\mathrm{Pr}$ & $\mathrm{Tr}$ & & & & & & & \\
\hline 1 & 0.75 & 1.333 & -0.3266 & -0.8442 & 0 & 53.07792 & 3 & 3 & 0.0000 \\
\hline 2 & 0.50 & 2.000 & 0.3665 & -0.1393 & 53.078 & 72.0783 & 3 & 2 & 0.3333 \\
\hline 3 & 0.25 & 4.000 & 1.2459 & 0.7550 & 72.078 & 96.1838 & 3 & 4 & 0.3333 \\
\hline 4 & & & & & 96.184 & $\sim$ & 3 & 3 & 0.0000 \\
\hline & & & & & & & 12 & 12 & 0.6667 \\
\hline
\end{tabular}

Agar distribusi frekuensi yang dipilih dapat diterima, maka harga $X^{2}$ hitung= $0,667<X^{2}$ Kritis $=21,026$ (Tabel) dapat diperoleh dengan menentukan taraf signifikasi $\alpha$ dengan derajat kebebasannya $5 \%$ sehingga Distribusi E.J Gumbel diterima.

\section{Uji Distribusi Frekwensi EJ Gumbel Metode : Smirnov-Kolmogorov Lokasi : Sungai Moyo}

Tabel 3. Uji Distr busi Frekwensi EJ Gumbel

\begin{tabular}{|c|c|c|c|c|c|c|c|}
\hline No & $\mathbf{X i}$ & $\mathbf{S n}(\mathbf{X})$ & $\mathbf{Y t}$ & $\mathbf{T r}$ & $\mathbf{P r}$ & $\mathbf{P x}(\mathbf{X})$ & $\Delta \max$ \\
\hline 1 & 21 & 0.0769 & -2.1535 & 1.000 & 0.9998 & 0.0002 & 0.0767 \\
2 & 30 & 0.1538 & -1.9455 & 1.001 & 0.9991 & 0.0009 & 0.1529 \\
3 & 62 & 0.2308 & -1.2058 & 1.037 & 0.9645 & 0.0355 & 0.1953 \\
4 & 69 & 0.3077 & -1.0440 & 1.062 & 0.9416 & 0.0584 & 0.2493 \\
5 & 78 & 0.3846 & -0.8360 & 1.111 & 0.9005 & 0.0995 & 0.2851 \\
6 & 79 & 0.4615 & -0.8129 & 1.117 & 0.8951 & 0.1049 & 0.3566 \\
7 & 82 & 0.5385 & -0.7436 & 1.139 & 0.8780 & 0.1220 & 0.4164 \\
9 & 93 & 0.6923 & -0.4893 & 1.243 & 0.8043 & 0.1957 & 0.4966 \\
10 & 99 & 0.7692 & -0.3506 & 1.319 & 0.7583 & 0.2417 & 0.5275 \\
11 & 103 & 0.8462 & -0.2582 & 1.377 & 0.7260 & 0.2740 & 0.5721 \\
12 & 105 & 0.9231 & -0.2119 & 1.409 & 0.7095 & 0.2905 & 0.6326 \\
\hline
\end{tabular}

Agar distribusi frekuensi Ej Gumbel dapat diterima, maka perbandingan dapat di lihat $\Delta \operatorname{Max}=0,6326<\Delta$ Kritis yaitu $=$ 0,375 dapat diperoleh dengan menentukan taraf signifikasi $\alpha$ dengan derajat kebebasannya $5 \%$ sehingga Distribusi EJ Gumbel ditolak.

\section{Perhitungan Curah Hujan Rancangan Metode Log Person type III}

Metode : Log Person type III Lokasi : Sungai Moyo 


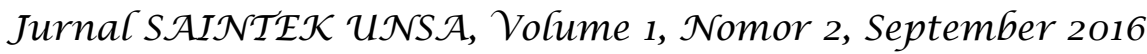

Tabel 4. Perhitungan Curah Hujan Rancangan Metode Log Person type III

\begin{tabular}{|c|c|c|c|c|}
\hline No. & $\mathbf{X i}$ & $\log X \mathbf{X}$ & $(\log X i-\log X r t)$ & $(\log X i-\log X r t)^{2}$ \\
\hline 1 & 21.0 & 1.322 & -0.518 & 0.268 \\
\hline 3 & 62.0 & 1.792 & -0.048 & 0.002 \\
\hline 4 & 69.0 & 1.839 & -0.001 & 0.000 \\
\hline 5 & 78.0 & 1.892 & 0.052 & 0.003 \\
\hline 6 & 79.0 & 1.898 & 0.057 & 0.003 \\
\hline 7 & 82.0 & 1.914 & 0.074 & 0.005 \\
\hline 8 & 89.0 & 1.949 & 0.109 & 0.012 \\
\hline 9 & 93.0 & 1.968 & 0.128 & 0.016 \\
\hline 10 & 99.0 & 1.996 & 0.155 & 0.024 \\
\hline 11 & 103.0 & 2.013 & 0.173 & 0.030 \\
\hline 12 & 105.0 & 2.021 & 0.181 & 0.033 \\
\hline \multicolumn{2}{|l|}{ Jumlah } & 22.1 & 0.00 & 0.53 \\
\hline \multicolumn{2}{|l|}{ Rerata } & 1.840 & 0.000 & 0.044 \\
\hline \multirow{2}{*}{\multicolumn{2}{|c|}{ Std. Deviasi }} & 0.219 & & \\
\hline & & -1.737 & & \\
\hline
\end{tabular}

Dari perhitungan Curah Hujan Rancangan Metode Log Person type III di dapatkan nilai rerata 1,840 , standar deviasi 0,219 dan skewness ( Cs ) - 1,737 Perhitungan Secara lengkap dapat dilihat pada Lampiran.

\section{Uji Distribusi Frekwensi Log Person type} III

Metode :Smirnov-Kolmogorov Lokasi : Sungai Moyo

Tabel 5. Uji Distr busi Frekwensi Log Person type III

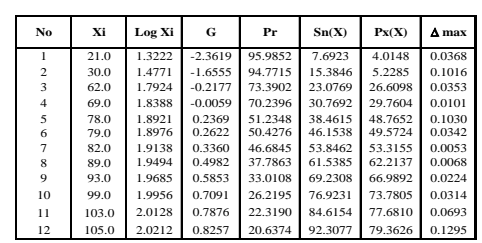

Agar distribusi frekuensi log Person type III dapat diterima, maka perbandingan dapat di lihat $\Delta$ Max = $0,1295<\Delta$ Kritis yaitu $=0,3897$ dapat diperoleh dengan menentukan taraf signifikasi $\alpha$ dengan derajat kebebasannya 5 \% sehingga Distribusi Log Person III diterima.

\section{Uji Distribusi Frekwensi Log Person type} III

$\begin{array}{ll}\text { Metode } & : \text { Chi Square } \\ \text { Lokasi } & : \text { Sungai Moyo } \\ \text { Jumlah kelas } & : \mathrm{K}=1+3,22 \log \mathrm{n} \\ & =1+3,22 \times 1,079 \\ & =4,475 \sim 4\end{array}$

Distribusi Tiap kelas 100\% k=100\% / $4=$ $25 \%$
Tabel 6. Uji Distribusi Frekwensi Log Person type III

\begin{tabular}{|c|c|c|c|c|c|c|c|}
\hline \multirow{2}{*}{ No } & \multicolumn{2}{|c|}{ Distribusi Prob. } & \multirow{2}{*}{ G } & \multirow{2}{*}{ Interval Kelas } & \multirow{2}{*}{ Ej } & \multirow{2}{*}{$0 \mathrm{j}$} & \multirow{2}{*}{$(0 \mathrm{j}-\mathrm{Ej})^{2} / \mathrm{Ej}$} \\
\hline & $\mathrm{Pr}$ & $\mathrm{Tr}$ & & & & & \\
\hline 1 & 0.75 & 1.333 & -0.5059 & $0-53.60448$ & 3 & 3 & 0.0000 \\
\hline 2 & 0.50 & 2.000 & 0.2755 & $53.604-79.53499$ & 3 & 3 & 0.0000 \\
\hline 3 & 0.25 & 4.000 & 0.7314 & $79.535-100.118$ & 3 & 3 & 0.0000 \\
\hline 4 & & & & 100.118 - & 3 & 3 & 0.0000 \\
\hline & & & & Jumlah & 12 & 12 & 0.0000 \\
\hline
\end{tabular}

Dari Hasi Perhitungan diatas, maka harga $X^{2}$ Cal $0,000<X^{2}$ Kritis 21,026 (Tabel) dapat diperoleh dengan menentukan taraf signifikasi $\alpha$ dengan derajat kebebasannya $5 \%$ sehingga Distribusi Log Person III diterima.

\section{Curah Hujan Rancangan BPS Sungai Moyo}

Tabel 7. Curah Hujan Rancangan BPS Sungai Moyo

\begin{tabular}{|c|c|c|c|}
\hline \multirow[b]{2}{*}{ No } & \multirow{2}{*}{$\begin{array}{l}\text { Periode } \\
\text { Tr } \\
\text { (Tahun) }\end{array}$} & \multicolumn{2}{|c|}{ CH Rancangan $(\mathrm{mm})$} \\
\hline & & $\overline{\text { EJ Gumbel }}$ & Log Pearson Type III \\
\hline 1 & 2 & 72.078 & 79.535 \\
\hline 2 & 5 & 103.147 & 104.834 \\
\hline 3 & 10 & 123.718 & 113.123 \\
\hline 4 & 25 & 149.709 & 117.979 \\
\hline 5 & 50 & 168.990 & 119.287 \\
\hline 6 & 100 & 188.130 & 119.299 \\
\hline 7 & 200 & 207.199 & 118.874 \\
\hline 8 & 500 & 232.357 & 120.958 \\
\hline 9 & 1000 & 251.371 & 124.513 \\
\hline \multicolumn{4}{|c|}{ Uji Smirnov-Kolmogorov } \\
\hline \multirow{2}{*}{\multicolumn{2}{|c|}{$\begin{array}{l}\Delta \text { Cal. Maximum, } \Delta \mathrm{P}_{\max }(\%) \\
\text { Signification of degree, } \alpha\end{array}$}} & 0.633 & 0.129 \\
\hline & & $5 \%$ & $\begin{array}{c}5 \% \\
0.390\end{array}$ \\
\hline Hipotesa & $\Delta$ Kritis, $\Delta \mathrm{P}_{\text {knitis }}(\%)$ & 0.375 & 0.390 \\
\hline \multicolumn{4}{|c|}{ Uji Chi Square } \\
\hline \multirow{4}{*}{\multicolumn{2}{|c|}{$\begin{array}{l}\text { Chi-Square calculate } \\
\text { Chi-Square critical } \\
\text { Free of degree, } v \\
\text { Signification of degree, } \alpha\end{array}$}} & 0.667 & 0.000 \\
\hline & & 21.026 & 21.026 \\
\hline & & 1 & 1 \\
\hline & & $5 \%$ & $5 \%$ \\
\hline \multicolumn{2}{|c|}{ Hipotesa } & Diterima & Diterima \\
\hline
\end{tabular}

Dari hasil perhitungan curah hujan rancangan berdasarkan uji smirnov kolmogorof dan uji chi square didapat distribusi terbaik menggunakan metode Log Pearson type III.

\section{Perhitungan Nilai Hidrograf Banjir Rencana}

Berikut adalah hasil analisa menggunakan metode distribusi gumbel dan distribusi log pearson type III. 


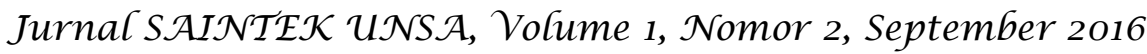

Tabel 8 . Perhitungan Nilai hidrograf Banjir Rencana

\begin{tabular}{|c|c|c|c|c|c|c|c|c|c|c|c|}
\hline \multirow[b]{2}{*}{ No } & \multirow{2}{*}{ jam } & \multirow{2}{*}{$\begin{array}{c}Q \\
\mathrm{~m}^{3} / \mathrm{d} / \mathrm{mm}\end{array}$} & \multicolumn{9}{|c|}{ Debit Banjir Rancangan Dengan Berbagai Kala Ulang } \\
\hline & & & 2 & 5 & 10 & 25 & 50 & \begin{tabular}{|l|l|}
100 \\
\end{tabular} & \begin{tabular}{|l|l|}
200 \\
\end{tabular} & 500 & 1000 \\
\hline & 0 & 0.00000 & 0.100 & 0.100 & 0.100 & $\begin{array}{l}0.100 \\
\end{array}$ & 0.100 & 0.100 & 0.100 & 0.100 & 0.100 \\
\hline & 0.638 & & & & & & & & & & \\
\hline & & & 2.396 & & & & & & 4.612 & 4.734 & 4.942 \\
\hline & 1.638 & & & 12.528 & 14.127 & & & 15.332 & 15.249 & 15.658 & 16.358 \\
\hline & 2 & & & & & & & 25.223 & & 25.761 & \\
\hline 6 & 2.638 & & & & & & & & & 51.862 & 4.192 \\
\hline & & & & & & & & 70.512 & & 72.018 & \\
\hline 8 & 3.638 & & & 94.482 & & 113.818 & & 115.781 & 115.149 & 118.255 & 123.575 \\
\hline 10 & & & & 120.746 & 136.270 & 145.462 & 147.949 & 147.972 & 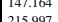 & 151.134 & 157.935 \\
\hline 11 & $\frac{4.008}{5}$ & & & .327 & 6.746 & 0.020 & & 213.13644 & 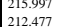 & 2218.2272 & 228.032 \\
\hline & & 3.6152 & & & & & & 6.593 & & 10068 & 200462 \\
\hline & & & & & & & & & & 0.556 & 20.462 \\
\hline & & & & & & & & 157.244 & 6.385 & 60.604 & 67.831 \\
\hline & & & & & & & & 124.504 & 3.825 & 127.165 & 2.886 \\
\hline & 10 & & & & & & & 99.429 & & 101.553 & 106.121 \\
\hline & & & & & & & & & & 84.069 & 87.849 \\
\hline & 12 & & & & & & & & & & \\
\hline & & & & & & & & & & & 62.594 \\
\hline 2 & 14 & & & & & & & & & & 581 \\
\hline & & & & & & & & & & & \\
\hline & 16 & & & & & & & & & $\begin{array}{l}37.579 \\
3.719\end{array}$ & 39.267 \\
\hline & & & & & & & & & & $\begin{array}{l}25.144 \\
20837\end{array}$ & 618 \\
\hline & & & & & & & & & & & 586 \\
\hline & & & & & & & & & & & \\
\hline & 21 & & & & & & & & & & \\
\hline 28 & 22 & & 8.5 & & & & & & & & 842 \\
\hline${ }_{30}^{29}$ & ${ }_{24}^{23}$ & $\begin{array}{l}0.2359 \\
0.2099\end{array}$ & $\begin{array}{l}7.586 \\
6.760\end{array}$ & $\begin{array}{l}12.167 \\
10.836\end{array}$ & $\begin{array}{l}13.719 \\
12.218\end{array}$ & 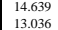 & $\begin{array}{l}14.887 \\
13.257\end{array}$ & $\begin{array}{l}14.890 \\
13.259\end{array}$ & $\begin{array}{l}14.809 \\
13.187\end{array}$ & $\begin{array}{l}15.206 \\
13541\end{array}$ & $\begin{array}{l}15.886 \\
14.146\end{array}$ \\
\hline & & & & & & $\frac{213.500}{20}$ & 217.150 & 217.184 & 215.997 & 221.827 & 231.811 \\
\hline
\end{tabular}

Dari data diatas, diambil nilai debit maksimum sebagai debit banjir untuk periode kalah ulang 50 tahun yaitu $217.150 \mathrm{~m} 3 /$ det.

\section{KESIMPULAN}

Kesimpulan yang dapat diambil dari laporan tugas Akhir "Studi perencanaan teknis bangunan pengendali sedimen Pada Sungai Moyo"

adalah sebagai berikut :

1. Kondisi sungai moyo pada saat musim hujan mengalami permasalahan banjir yang diakibatkan oleh sedimentasi yang terjadi pada bendung moyo sehingga di rencanakan bangunan pengendali sedimen dibagian hulu bendung

2. Didalam Analisis hidrologi bangunan pengendali sedimen digunakan banjir rencana dengan kala ulang 50 tahun Diman Q50 $217.15 \mathrm{~m} 3 / \mathrm{dt}$.

3. Dari hasil perencanaan bangunan pengendali sedimen didapat elevasi puncak mercu +28.300 dengan tinggi efektif sebesar $3.5 \mathrm{M}$ dan kedalaman pondasi sebesar $1.50 \mathrm{M}$

4. Dari hasil analisis dibuat gambar perencanaan bangunan pengendali sedimen antara lain :
a. Denah
b. Potongan $A-A$
c. Potongan $B-B$

5. Dari hasil Analisis rencana anggaran biaya pembangunan bangunan pengendali sedimen di dapat biaya sebesar Rp.1,390,873,250.00

\section{SARAN}

Saran - saran yang dapat disampaikan pada tugas akhir ini adalah sebagai berikut:

1. Pengendalian erosi dan sedimentasi dengan pembangunan bangunan pengedali Sedimen tidak akan memberikan hasil yang optimal apabila masih banyak lahan - lahan di sekitar das yang rusak yang menyebabkan terjadinya erosi. Untuk mengulangi hal tersebut, perlu dilakukan konservasi lahan secara menyeluruh di DAS tersebut,misal: pengolahan tanah menurut kontur, penggunaan teknik pertanian di lahan berupa lereng, dan sebagainya.

2. Untuk mendapatkan perhitungan desain yang benar-benar akurat, maka pemakaian metode perhitungan harus benar-benar tepat dengan kondisi yang ada.

\section{DAFTAR PUSTAKA}

Anonim, 1997. Irigasi Dan Bangunan Air. Penerbit Gunadarma, Jakarta, 1997 Anonim, 2008, Laporan Akhir Perencanaan Pembangunan Daerah Irigasi Senampar. CV. Indra Utama

Anonim. 2016. Data Curah Hujan Dan Hujan Harian. Dinas Pertanian Tanaman Pangan dan Holtikultura Kabupaten Sumbawa.

Arsyad, S. 2000. Konservasi Tanah Dan Air. UPT Produksi Media Informasi. Lembaga Sumber daya Informasi. Institut Pertanian Bogor, IPB Press, Bogor.

Asdak, Chay. 2004. Hidrologi Dan Pengelolaan Daerah Aliran Sungai. Cetakan Ketiga (revisi). Gadjah Mada University Press. Yogyakarta.

Asdak, Chay. 2007. Hidrologi Dan Pengelolaan Daerah Aliran Sungai. Yokyakarta: Gajah mada University Press. 


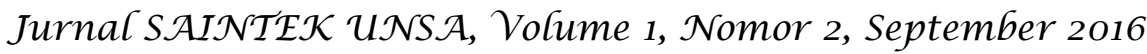

Asdak ,Chay. 1995. Hidrologi Dan Pengelolaan Daerah Aliran Sungai. Yogyakarta : Gajah Mada University Press.

Asdak, Chay. 2004. Hidrologi dan Pengelolaan Daerah Aliran Sungai. Cetakan Ketiga (revisi). Gadjah Mada University Press. Yogyakarta.

Asdak, Chay, 2010. Hidrologi dan Pengelolaan Daerah Aliran Sungai, Gadjah

Mada University Press, Yogyakarta.

Chow, VT. 1989. Hidrolika Saluran Terbuka. Erlangga, Jakarta

Linsley, R. K., 1996. Hidrologi Untuk Insinyur, Erlangga, Jakarta.

Morgan RPC. 1990. Soil Erotion and Conservation. New York: Longman Scientific ang Technical. John Wiley and Sons, Inc.

Purnama, A, 2011. STUDI KELAYAKAN PEMBANGUNAN PEMBANGKIT LISTRIK TENAGA MIKROHIDRO Studi Kasus: PLTMH Minggir pada saluran irigasi Minggir di Padukuhan Klagaran Desa Sendangrejo Kecamatan Minggir Kabupaten Sleman, Jurnal Unsa Progress. Vol.10, No.15, Oktober, Universitas Samawa, Sumbawa Besar.

Purnama, A, 2015. Konsentrasi Sedimen Suspensi pada Belokan $57^{\circ}$ Saluran Terbuka, Jurnal Unsa Progress. Vol.1, No.3, Oktober, Universitas Samawa, Sumbawa Besar.

Purnama, A, 2016. Analisis Distribusi Kecepatan Dan Sedimen Pada Tikungan $55^{\circ}$ Saluran Terbuka Tampang Segi Empat, Jurnal Unsa Progress. Vol.21, No.3, Juli, Universitas Samawa, Sumbawa Besar. 